\title{
Exploring the isopycnal mixing and helium-heat paradoxes in a suite of Earth system models
}

\author{
A. Gnanadesikan ${ }^{1}$, M.-A. Pradal ${ }^{1}$, and R. Abernathey ${ }^{2}$ \\ ${ }^{1}$ Department of Earth and Planetary Sciences, Johns Hopkins University, Baltimore, MD, USA \\ ${ }^{2}$ Department of Earth and Environmental Sciences, Columbia University, New York, NY, USA \\ Correspondence to: A. Gnanadesikan (gnanades@jhu.edu)
}

Received: 11 October 2014 - Published in Ocean Sci. Discuss.: 20 November 2014

Revised: 10 June 2015 - Accepted: 27 June 2015 - Published: 27 July 2015

\begin{abstract}
This paper uses a suite of Earth system models which simulate the distribution of He isotopes and radiocarbon to examine two paradoxes in Earth science, each of which results from an inconsistency between theoretically motivated global energy balances and direct observations. The helium-heat paradox refers to the fact that helium emissions to the deep ocean are far lower than would be expected given the rate of geothermal heating, since both are thought to be the result of radioactive decay in Earth's interior. The isopycnal mixing paradox comes from the fact that many theoretical parameterizations of the isopycnal mixing coefficient $A_{\text {Redi }}$ that link it to baroclinic instability project it to be small (of order a few hundred $\mathrm{m}^{2} \mathrm{~s}^{-1}$ ) in the ocean interior away from boundary currents. However, direct observations using tracers and floats (largely in the upper ocean) suggest that values of this coefficient are an order of magnitude higher. Helium isotopes equilibrate rapidly with the atmosphere and thus exhibit large gradients along isopycnals while radiocarbon equilibrates slowly and thus exhibits smaller gradients along isopycnals. Thus it might be thought that resolving the isopycnal mixing paradox in favor of the higher observational estimates of $A_{\text {Redi }}$ might also solve the helium paradox, by increasing the transport of mantle helium to the surface more than it would radiocarbon. In this paper we show that this is not the case. In a suite of models with different spatially constant and spatially varying values of $A_{\text {Redi }}$ the distribution of radiocarbon and helium isotopes is sensitive to the value of $A_{\text {Redi }}$. However, away from strong helium sources in the southeastern Pacific, the relationship between the two is not sensitive, indicating that large-scale advection is the limiting process for removing helium and radiocarbon from the deep ocean. The helium isotopes, in turn, suggest
\end{abstract}

a higher value of $A_{\text {Redi }}$ below the thermocline than is seen in theoretical parameterizations based on baroclinic growth rates. We argue that a key part of resolving the isopycnal mixing paradox is to abandon the idea that $A_{\text {Redi }}$ has a direct relationship to local baroclinic instability and to the so-called "thickness" mixing coefficient $A_{\mathrm{GM}}$.

\section{Introduction}

Because the ocean is highly stratified and weakly forced, tracer mixing occurs predominantly along surfaces of constant neutral density (Ledwell et al., 1998). The turbulent flux associated with mesoscale eddies is usually parameterized as downgradient eddy diffusion with a coefficient $A_{\text {Redi }}$ (Redi, 1982; Griffies et al., 1998). Considering only one dimension for simplicity, the meridional flux of some tracer $C$ along an isopycnal is then

$F_{C}=\overline{v^{\prime} C^{\prime}}=-A_{\text {Redi }} \frac{\partial \bar{C}}{\partial s}$,

where the overline denotes an average (ensemble or time), $v$ is the meridional velocity along the isopycnal and $\partial / \partial s$ is a gradient oriented along that isopycnal. The size of $A_{\text {Redi }}$ obviously has the potential to play a major role in determining the rate of exchange between the interior of the ocean and the surface. It is generally assumed that all passive tracers experience the same value of $A_{\text {Redi }}$, though it is not clear that this should be the case for very short-lived tracers or in the presence of spatially variable sources and sinks.

However, there is not an operational consensus in the ocean modeling community about how to represent $A_{\text {Redi }}$. 
This is in part because $A_{\text {Redi }}$ represents only one dynamically important process associated with eddies. In addition to stirring fluid parcels along isopycnal surfaces, eddies act to flatten those isopycnal surfaces as a result of baroclinic instability, releasing available potential energy. This process was parameterized by Gent and McWilliams (1990) in terms of an "eddy Stokes drift" arising from correlations between the thickness of an isopycnal layer $h$ and the velocities $v$. By analogy with Eq. (1) (again considering only the meridional dimension for simplicity),

$v_{*}=\overline{v^{\prime} h^{\prime}} / \bar{h}=-A_{\mathrm{GM}} \frac{\partial \bar{h} / \partial y}{\bar{h}}=-A_{\mathrm{GM}} \frac{\partial S_{\rho}^{y}}{\partial z}$,

where $v_{*}$ is the meridional velocity associated with the overturning eddies, $A_{\mathrm{GM}}$ is the so-called "thickness diffusivity" (in reality the diffusivity is implemented as a diffusivity in interface height) and $S_{\rho}^{y}$ is the slope of isopycnal surfaces in the $y$ direction. As described below, many published models use the following assumptions to constrain $A_{\text {Redi }}$.

1. It is equal to $A_{\mathrm{GM}}$ because the same eddies accomplish the mixing (Griffies, 1998).

2. It is therefore largest in boundary currents where eddy kinetic energy is most intense and baroclinicity is largest.

3. Because the size of the observed overturning circulation puts limits on how large $A_{\mathrm{GM}}$ can be in these boundary currents (Gnanadesikan, 1999), $A_{\text {Redi }}$ is only on the order of a few hundred square meters per second in the gyre interiors and in the deep ocean.

Examples of models which implement these assumptions include GFDL CM2.0 (Geophysical Fluid Dynamics Laboratory; Gnanadesikan et al., 2006), CSIRO Mk3.6, (Commonwealth Scientific and Industrial Research Organisation; Gordon et al., 2010) NCAR CESM (National Center for Atmospheric Research-Community Earth System Model; Danabasoglu et al., 2012) and NorESM (Norwegian Earth System Model Bentsen et al., 2013). In the GFDL ESM2G model (Dunne et al., 2012) $A_{\mathrm{GM}}$ and $A_{\text {Redi }}$ are both given by a baroclinic growth rate parameterization but have different minimum values. Other models use relatively small constant values for $A_{\text {Redi }}$, including the Hadley Centre's HadCM3 and HadGEM $\left(500 \mathrm{~m}^{2} \mathrm{~s}^{-1}\right.$, Jones et al., 2011), GFDL CM2.1 $\left(600 \mathrm{~m}^{2} \mathrm{~s}^{-1}\right.$, Gnanadesikan et al., 2006) and GFDL ESM2M (also $600 \mathrm{~m}^{2} \mathrm{~s}^{-1}$, Dunne et al., 2012).

However, these assumptions lead to a paradox. Observational estimates of $A_{\text {Redi }}$ based on tracers and floats (largely near the ocean surface) show very large values for this parameter, in the range of thousands of square meters per second. Only a few models (the CMCC ESM of Fogli et al., 2009, and CNRM CM3 of Salas-Melia et al., 2005) use relatively large values of $A_{\text {Redi }}\left(2000 \mathrm{~m}^{2} \mathrm{~s}^{-1}\right.$ in both cases) in the ocean interior. We term this order of magnitude difference between the values if $A_{\text {Redi }}$ emerging from theory and direct observations the isopycnal mixing paradox.

One reason this paradox has remained unresolved is that physical properties in ocean-only models are far less sensitive to $A_{\text {Redi }}$ than they are to $A_{\mathrm{GM}}$, as surfaces of constant temperature, salinity and density often align with each other. However, $A_{\text {Redi }}$ can have a more significant impact on the distribution of tracers that have interior sources and sinks. Measurements of such tracers thus offer the possibility of constraining $A_{\text {Redi }}$. Gnanadesikan et al. (2013) demonstrated that $A_{\text {Redi }}$ had a first-order impact on the distribution of hypoxic waters within a suite of Earth system models and Gnanadesikan et al. (2015) show that it impacts anthropogenic carbon uptake.

In this paper we expand on Gnanadesikan et al. (2013) to look at two other tracers. The first is primordial mantle helium-3. Incorporated into Earth's interior when it formed, mantle helium is transported from the interior to regions where new ocean crust forms. This produces a strong helium isotope anomaly,

$\delta^{3} \mathrm{He}=\left({ }^{3} \mathrm{He} /{ }^{4} \mathrm{He}\right)_{\text {sample }} /\left({ }^{3} \mathrm{He} /{ }^{4} \mathrm{He}\right)$ atm -1,

as seen in Fig. 1a. As waters are brought to the surface, the helium exchanges rapidly with the atmosphere and the isotopic signature is destroyed. The Pacific is enriched in mantle helium both because waters are out of contact with the atmosphere in this basin for long periods of time (Khatiawala et al., 2012) and because the ridge centers in the Pacific spread faster, producing more new crust and degassing more ${ }^{3} \mathrm{He}$ (Farley et al., 1995).

The second tracer is radiocarbon. Produced by galactic cosmic rays interacting with nitrogen in the upper atmosphere, radiocarbon equilibrates with the upper ocean on a relatively long timescale (of order 10 years for a $100 \mathrm{~m}$ deep layer). This equilibration is slow because air-sea gas exchange is controlled by the difference in $p \mathrm{CO}_{2}$, which accounts for only a few percent of the total dissolved inorganic carbon and because equilibrating this entire pool depends on the gross, rather than the net exchange. Despite this, the vast majority of radiocarbon in the air-sea system $(98 \%)$ ends up in the ocean. There it decays with a halflife of 5730 years, corresponding to an e-folding time of 8270 years. Radiocarbon is measured in $\Delta^{14} \mathrm{C}$ units, where a value of 0 means that the radiocarbon is what would be expected for water at equilibrium with the preindustrial atmosphere and $-1000 \%$ means no radiocarbon is found in the sample. The $\Delta$ is used to indicate that corrections have been made for mass-dependent fractionation processes using ${ }^{13} \mathrm{C}$, (for more detail see Emerson and Hedges, 2008). As seen in Fig. 1b the highest radiocarbon in the deep ocean is found in the North Atlantic where freshly ventilated deep waters have had the time to equilibrate with the atmosphere. Waters brought to the surface in the Southern Ocean do not 


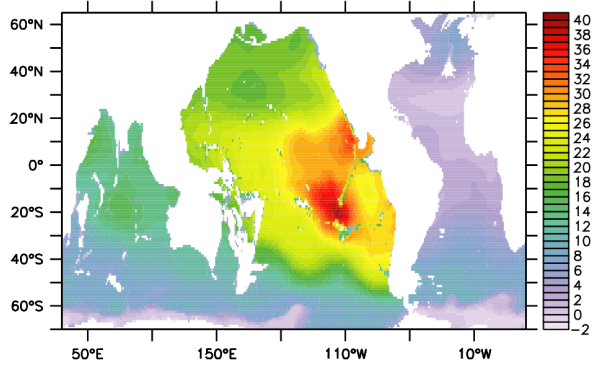

(A) $\delta^{3} \mathrm{He}$ on $\sigma_{2}=36.95$

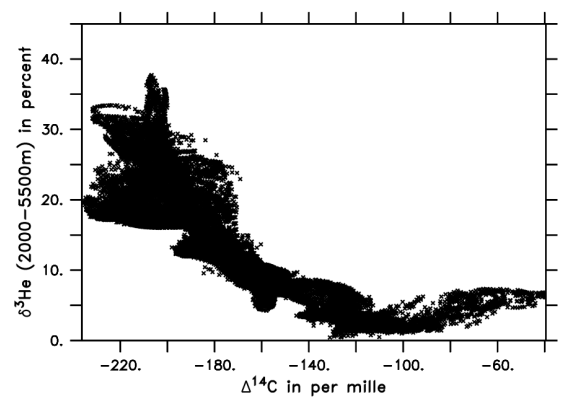

(C) Global $\delta^{3} \mathrm{He}$ vs. $\Delta^{14} \mathrm{C}$

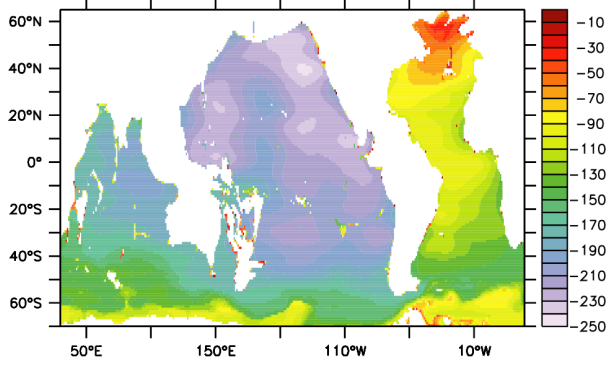

(B) $\Delta^{14} \mathrm{C}$ on $\sigma_{2}=36.95$

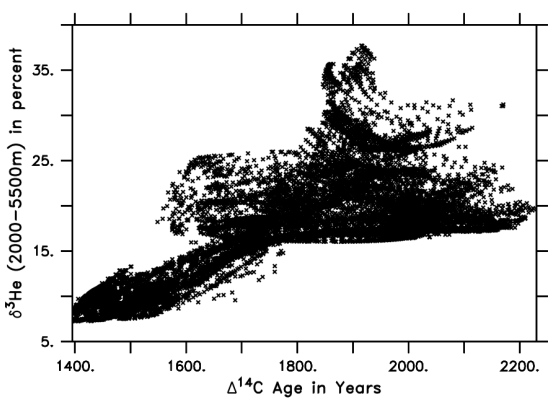

(D) Pacific $\delta^{3} \mathrm{He}$ vs. Radiocarbon Age

Figure 1. $\delta^{3} \mathrm{He}$ and radiocarbon in the ocean. (a) $\delta^{3} \mathrm{He}$ from Bianchi et al. (2010) on $\sigma_{2}$ ( potential density relative to $2000 \mathrm{~m}$ minus $1000 \mathrm{~kg} \mathrm{~m}^{-3}$ ) of 36.95. (b) $\Delta^{14} \mathrm{C}$ on $\sigma_{2}=36.95$ from Key et al. (2004). (c) Vertically averaged $\delta^{3} \mathrm{He}$ vs. vertically averaged $\Delta^{14} \mathrm{C}(2000$ $5500 \mathrm{~m}$ ). (d) Vertically averaged $\delta^{3} \mathrm{He}$ vs. radiocarbon age, 2000-5500 m, Pacific sector only.

stay at the surface long enough to have their radiocarbon reset and so both deep and surface radiocarbon in the Southern Ocean lie in the range of -120 to $-130 \%$. As waters flow into the Indian and Pacific oceans, radiocarbon continues to drop, with the lowest values (around $-240 \%$ ) found in the North Pacific. While the above-air nuclear bomb tests added a significant amount of radiocarbon to the ocean-atmosphere system, relatively little of this is seen in the deep ocean (Key et al., 2004).

The relationship between deep radiocarbon (averaged below $2000 \mathrm{~m}$ ) and deep $\delta^{3} \mathrm{He}$ (Fig. 1c) shows an approximately linear relationship, particularly as $\Delta^{14} \mathrm{C}$ ranges from -100 to $-180 \%$. Atlantic waters show a different slope, perhaps because of potential incorporation of radiocarbon and $\delta^{3} \mathrm{He}$ resulting from nuclear bomb tests. Computing a radiocarbon age from the observations Age $=-8270 \times \ln (1+$ $\Delta^{14} \mathrm{C} / 1000$ ), we see a general increase of $\delta^{3} \mathrm{He}$ with age in the Pacific Ocean (Fig. 1d). That the relationship is not perfectly linear is expected, given that the sink of radiocarbon is much more homogeneous than the sources of mantle He.

Together, these tracers bear on an interesting paradox in solid Earth geophysics. By combining the ratio of ${ }^{3} \mathrm{He}$ to ${ }^{4} \mathrm{He}$ in hydrothermal waters, and estimating the inventory of mantle ${ }^{3} \mathrm{He}$ in the ocean, one can estimate the inventory of mantle ${ }^{4} \mathrm{He}$. Given the age of the ocean, one can estimate the flux of mantle ${ }^{3} \mathrm{He}$ to the ocean, which can then be scaled to estimate fluxes of mantle ${ }^{4} \mathrm{He}$ and also of other elements. If this ${ }^{4} \mathrm{He}$ results from the decay of atomic nuclei ${ }^{238} \mathrm{U}$, the resulting helium flux should be consistent with the geothermal heating of the deep ocean (O'Nions and Oxburgh, 1983; Turner and Stuart, 1992). As we will explain in more detail below, attempts to match the relationship shown in Fig. 1c result in estimates of ${ }^{4} \mathrm{He}$ flux that are much lower than required to balance the observed geothermal heat flux. This has been referred to as the helium-heat paradox (Anderson, 1998). Like the isopycnal mixing paradox, it is based in an inconsistency between top-down budgets and direct measurements.

This paper examines two connections between the tracers and isopycnal mixing. First, it examines whether resolving the isopycnal mixing paradox in favor of higher values of $A_{\text {Redi }}$ more consistent with observations could allow for a different relationship between mantle helium and radiocarbon. As discussed in Sect. 2, insofar as isopycnal mixing brings deep water to the surface and returns it rapidly to depth, it would be expected to vent mantle helium without necessarily replenishing radiocarbon. Were this a dominant transport process, it would allow for the relationship in Fig. 1c with higher mantle helium fluxes. We show that this is not the case. Second, we examine whether the deep distribution of $\delta^{3} \mathrm{He}$ can be used to put any constraints on mixing within the deep ocean below the main thermocline, where direct measurements are sparse. We argue that it does, and that the values found are larger than in many global circulation models.

The paper is structured as follows. Section 2 goes into more detail regarding the isopycnal mixing and helium para- 
doxes. Section 3 describes a new suite of Earth system models that has been run to explore the dependence of physical climate and tracer distributions on $A_{\text {Redi }}$. Section 4 examines the relationship between mantle helium and radiocarbon in these simulations and concludes that for a realistic range of $A_{\text {Redi }}$ this relationship is relatively insensitive to the value used. Section 5 examines distributions of $\delta^{3} \mathrm{He}$, with a focus on the southeastern Pacific, and concludes that relatively high values of $A_{\text {Redi }}$ are most consistent with observations. The results of the Earth system models thus add support for the existence of both paradoxes. While resolution of the helium paradox is beyond the expertise of the authors of this paper, potential resolutions to the isopycnal mixing paradox are discussed in Sect. 6.

\section{Two paradoxes in Earth science}

\subsection{The isopycnal mixing paradox}

Dimensionally

$A_{\mathrm{GM}, \text { Redi }}=L^{2} / T$,

where $L$ is a length scale and $T$ a timescale. Most modern climate models use some version of the closure first proposed by Green (1970) where $1 / T$ is given by the growth rate of baroclinically unstable waves assuming the growth rate scales as that described by Eady (1949). In this case, assuming thermal wind balance, one obtains

$$
1 / T=f / R i^{1 / 2}=f|\mathrm{~d} U / \mathrm{d} z| / N \approx\left|S_{\rho}\right| N,
$$

where $S_{\rho}$ is the slope of density surfaces (Visbeck et al., 1997). In climate models, the slope is usually taken as some average slope over a range of depths (for example 100$2000 \mathrm{~m}$ in Gnanadesikan et al., 2006). All else being equal, these approximations predict that growth rates and diffusion coefficients should be very small in the center of the subtropical gyres where isopycnals are relatively flat. An example is shown in Fig. 2a for the GFDL CM2Mc model of Galbraith et al. (2011). Because of its role in moving light tropical waters into polar regions, particularly within the Southern Ocean, $A_{\mathrm{GM}}$ has a first-order impact on the large-scale circulation of the ocean (Danabasoglu et al., 1994; Gnanadesikan, 1999). Values much larger than $1000 \mathrm{~m}^{2} \mathrm{~s}^{-1}$ in the main pycnocline tend to produce unrealistic smoothing of the pycnocline and suppression of the large-scale overturning circulation unless unrealistically high values of vertical mixing are applied in the tropics. Thus, in models where $A_{\text {Redi }}=A_{\mathrm{GM}}$, values applied in the center of subtropical gyres are often very low, on the order of a few hundred square meters per second.

Measuring $A_{\mathrm{GM}}$ directly from observations in nearly impossible, but several observational estimates of $A_{\text {Redi }}$ do exist; these estimates seem incompatible with the values of
$A_{\mathrm{GM}}$ described above. Modern estimates of $A_{\text {Redi }}$ using a variety of methods find relatively large values in the ocean interior. For example Ledwell et al. (1998), using $\mathrm{SF}_{6}$ released into the thermocline, estimated an east-west diffusion of $1500 \mathrm{~m}^{2} \mathrm{~s}^{-1}$ and a north-south diffusion of $600 \mathrm{~m}^{2} \mathrm{~s}^{-1}$. Baynte et al. (2013), looking at the Guinea Dome, found a value of $1000-1200 \mathrm{~m}^{2} \mathrm{~s}^{-1}$ in the east-west direction and $500 \mathrm{~m}^{2} \mathrm{~s}^{-1}$ in the north-south direction. Estimates with subsurface floats yield even larger values, with Bauer et al. (1998) estimating values of $2000-9000 \mathrm{~m}^{2} \mathrm{~s}^{-1}$ in the equatorial Pacific and Ollitraut and Colin de Verdiere (2002) finding values of $1500-3000 \mathrm{~m}^{2} \mathrm{~s}^{-1}$ in the North Atlantic. A recently developed "pseudo-observational" approach uses satellite-derived surface geostrophic velocities to drive tracer or particle transport simulations (Shuckburgh and Haynes, 2003; Marshall et al., 2006; Shuckburgh et al., 2009; Rypina et al., 2012). Lateral diffusion coefficients can then be calculated directly from such simulations. Abernathey and Marshall (2013) applied this method globally, producing the map of near-surface $A_{\text {Redi }}$ shown in Fig. 2c. Finally, eddy diffusion coefficients can be estimated from eddy-resolving numerical models (Abernathey et al., 2010; Fox-Kemper et al., 2012; Bachman et al., 2015). All these diverse estimates suggest that $A_{\text {Redi }}$ can be several times larger than the values commonly used for $A_{\mathrm{GM}}$. This is the isopycnal mixing paradox.

One question is whether this paradox persists into the deep ocean. There are only a few direct estimates of $A_{\text {Redi }}$ below the main thermocline. Ledwell and Watson (1991), in the Santa Barbara Basin, found a diffusion coefficient of 10 $20 \mathrm{~m}^{2} \mathrm{~s}^{-1}$ on spatial scales of $10 \mathrm{~km}$. Rye et al. (2012) in the Brazil Basin found a value of around $100 \mathrm{~m}^{2} \mathrm{~s}^{-1}$. Both of these, however, are at depths where lateral motion is likely to be strongly physically constrained by topography. There are no observational studies of which we are aware that directly estimate lateral diffusion between the base of the thermocline and depths associated with the tops of the mid-ocean ridges. In the few models where it is allowed to vary with depth, $A_{\mathrm{GM}}$ is assumed to drop in the deep ocean, as eddy kinetic energy is lower there. A zonal average of $A_{\mathrm{GM}}$ illustrating this is shown for the NCAR CESM model (Danabasoglu et al., 2012) in Fig. 2b. However, if the surface values of $A_{\text {Redi }}$ are too low, forcing it to decrease with depth may actually give less realistic deep values than the vast majority of parameterizations which simply prescribe values of 500$1000 \mathrm{~m}^{2} \mathrm{~s}^{-1}$ uniformly throughout the water column. Evaluating the extent to which this is the case is a major thrust of this paper.

One possible resolution of the paradox is the highly anisotropic nature of eddy transport. Rypina et al. (2012) and Fox-Kemper et al. (2012) show that eddy diffusion can be up to 10 times stronger in one direction (generally the zonal direction) than in the perpendicular direction. Yet all the climate models used in the CMIP5 (Coupled Model Intercomparison Project Phase 5) exercise employ isotropic (scalar) 

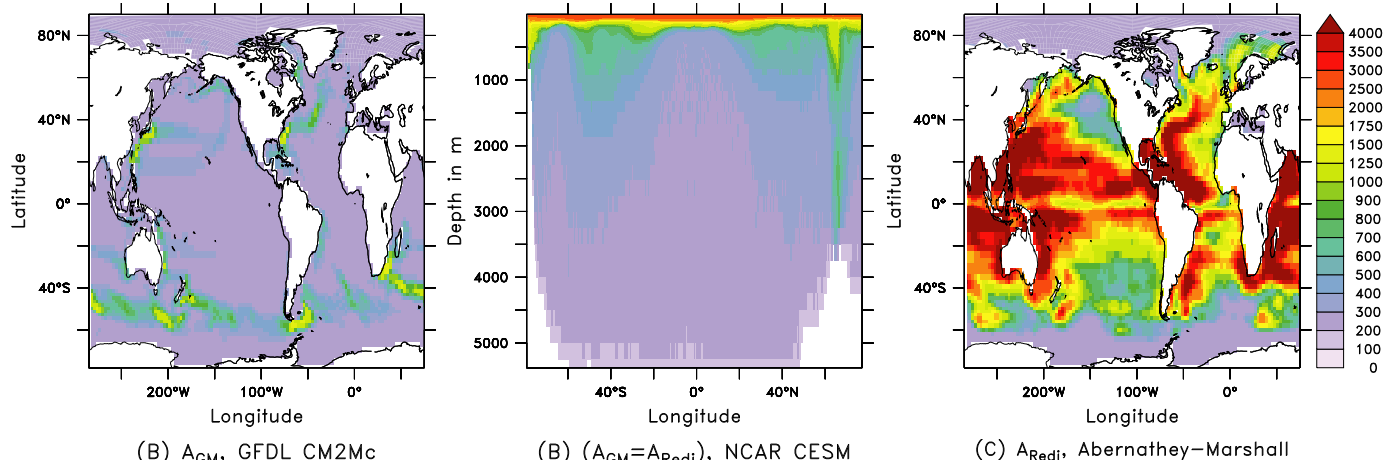

(C) A Redi, Abernathey-Marshall

Figure 2. Examples of $A_{\mathrm{GM}}$ and $A_{\mathrm{Redi}}$. (a) Vertically uniform $A_{\mathrm{GM}}$ from Galbraith et al. (2011). (b) Horizontal average of $A_{\mathrm{Redi}}=A_{\mathrm{GM}}$ from Danabasoglu et al. (2012). (c) Surface $A_{\text {Redi }}$ from observationally based calculation of Abernathey and Marshall (2013).

diffusivities for both $A_{\mathrm{GM}}$ and $A_{\text {Redi }}$. Experiments are ongoing regarding the consequences of anisotropic eddy diffusion for ocean models (Reckinger and Fox-Kemper, 2015). It is not clear, however, how well the observational estimates capture the details of anisotropy, given that a particular challenge in making such measurements is removing imperfectly known background shear flows (see for example LaCasce et al., 2014, who resolved this issue by looking at the crossstream diffusivity only). Such shear flows may also cause tilts in the major and minor axes of the dispersion tensor that reflect resolved flows rather than details of the turbulence. Employing higher subgrid-scale diffusivities in the alongstream direction in models where one already resolves the large-scale flow may thus count the impact of the shear dispersion twice.

Here, instead, we investigate another possible resolution: the non-equivalence between $A_{\mathrm{GM}}$ and $A_{\text {Redi }}$. Despite the common assumption that they are equal, there is ample evidence that the two coefficients can differ significantly. Linear quasigeostrophic theory can be used to show that the diffusion coefficient governing lateral buoyancy transport (corresponding to $A_{\mathrm{GM}}$ ) is very different from the coefficient governing along-isopycnal PV (potential vorticity) transport, which is asymptotically equal to $A_{\text {Redi }}$ (Smith and Marshall, 2009; Vollmer and Eden, 2013). This theory has been tested in fully nonlinear primitive equation simulations (Abernathey et al., 2013). These studies all show $A_{\text {Redi }}$ to be larger than $A_{\mathrm{GM}}$. Our experiments are designed to test whether elevated values of $A_{\text {Redi }}$ throughout the water column give unrealistic results for helium isotopes and radiocarbon.

\subsection{The helium-heat paradox}

Given a decay of ${ }^{238} \mathrm{U}$ of $4.26 \mathrm{MeV}=6.02 \times 10^{-13} \mathrm{~J}$ and a ratio of $R={ }^{3} \mathrm{He} /{ }^{4} \mathrm{He}$ of $1.6 \times 10^{-5}$ as in Craig et al. (1975), we expect one molyear ${ }^{-1}$ of ${ }^{3} \mathrm{He}$ to be associated with a global heat flux of about $800 \mathrm{MW}$. It is estimated that $\mathrm{U}$ decay contributes about $10-20 \mathrm{TW}$ of heating, implying a flux of around $12500-25000 \mathrm{~mol}^{3} \mathrm{He}_{\mathrm{year}}{ }^{-1}$. However, Craig et al. (1975), using a box model calibrated with observations of ${ }^{3} \mathrm{He}$, estimated a much lower flux of 1070 molyear $^{-1}$. This has led to suggestions from geochemists that the mantle as a whole does not convect, so that helium is trapped in the deep mantle while heat escapes (O'Nions and Oxburgh, 1983). While alternative explanations for this difference have been proposed (see for example Harrison and Ballentine, 2003) the exact value of the mantle helium flux remains an important calibration point for geochemistry.

Box models are, however, a crude representation of the true rate at which the ocean is ventilated. As each box is rapidly homogenized, the effective transport of tracer from the deep ocean to the surface may be much larger than in the real world. This means that box models with the right mean overturning fluxes could overestimate the speed at which tracers make it out of the deep ocean, and thus would require too large a source of ${ }^{3} \mathrm{He}$ in the deep ocean. On the other hand, the neglect of mixing fluxes may mean that box models can underestimate the true flux.

Dutay et al. (2004) simulated helium isotopes in a suite of ocean general circulation models, which (presumably) have a more realistic representation of the processes that overturn the ocean. However, this paper found large ranges in the inventory of mantle helium. Given the differences in model construction it was far from clear why this was the case. Bianchi et al. (2010) revisited this problem using a suite of ocean-only models developed to look at the differing roles of vertical and lateral diffusion in setting global circulation. In these models $A_{\mathrm{GM}}$ and $A_{\text {Redi }}$ were varied together, with the result that increasing the lateral mixing generally reduced vertical exchange. Examination of the relationship between $\delta^{3} \mathrm{He}$ and $\Delta^{14} \mathrm{C}$ in these models showed that those models with the most realistic radiocarbon, and thus presumably the most realistic ventilation of the deep ocean, tended to retain too much mantle ${ }^{3} \mathrm{He}$. The solution proposed was to reduce the flux of mantle ${ }^{3} \mathrm{He}$ yet further to 527 mol year $^{-1}$. 


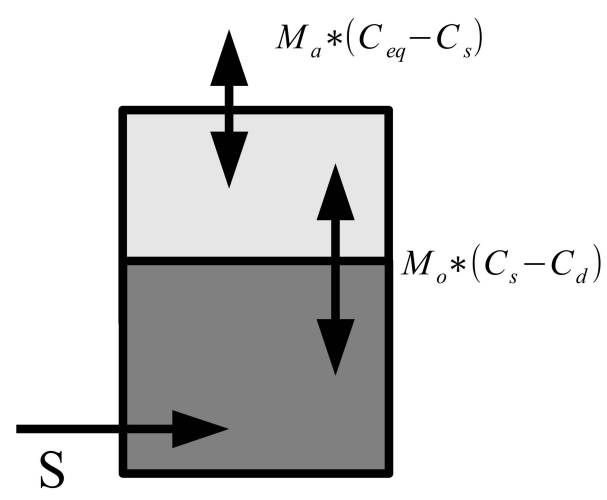

Figure 3. Two box schematic of a tracer with a source (or sink) in the deep ocean, the signal of which is transported to the surface box by mass transport $M_{\mathrm{O}}$ and equilibrated with the atmosphere by mass transport $M_{\mathrm{a}}$.

However, if $A_{\text {Redi }}$ changes are not directly tied to changes in $A_{\mathrm{GM}}$, as may be the case in the real ocean, the picture is potentially different. As shown in Pradal and Gnanadesikan (2014), increasing $A_{\text {Redi }}$ tends to destratify the high latitudes, allowing more exchange with the deep ocean and causing sea ice to retreat. Thus, increasing $A_{\text {Redi }}$ would be expected to reduce mantle ${ }^{3} \mathrm{He}$. The impact on radiocarbon is, however, less clear, given the long timescales involved in equilibration of carbon isotopes. An illustrative model of this is schematized in Fig. 3, in which a source of tracer is introduced into the deep box, circulation transports tracer between the interior box and the surface box producing a flux $M_{\mathrm{o}} \times\left(C_{d}-C_{\mathrm{s}}\right)$ and gas exchange restores the surface box to an equilibrium concentration with a flux $M_{\mathrm{a}} \times\left(C_{\mathrm{s}}-C_{\mathrm{eq}}\right)$. At equilibrium, both fluxes are equal to $S$ and the deep concentration is just

$C_{d}=C_{\mathrm{eq}}+S \times\left(1 / M_{\mathrm{o}}+1 / M_{\mathrm{a}}\right)$

and similarly

$C_{\mathrm{s}}=\frac{C_{d} \times M_{\mathrm{o}}+C_{\mathrm{eq}} \times M_{\mathrm{a}}}{M_{\mathrm{o}}+M_{\mathrm{a}}}$.

Suppose (as we do) that the deep Pacific is primarily ventilated from the Southern Ocean. For radiocarbon, the surface concentrations in the Southern Ocean are closer to the deep ocean mean of $-170 \%$ o than to zero, implying that $M_{\mathrm{o}}$ is actually a little bigger than $M_{\mathrm{a}}$ (consistent with the idea that it takes about 10 years to equilibrate the surface mixed layer). Thus, about half of the buildup of radiocarbon in the deep Pacific is due to slow gas exchange and will not be changed by increasing the ocean circulation. By contrast, helium isotopes at the surface of the Southern Ocean are in equilibrium with the atmosphere, implying a much larger $M_{\mathrm{a}}$. This implies that helium is more sensitive to changes in mixing than is radiocarbon. Could resolving the isopycnal mixing paradox by breaking $A_{\text {Redi }}$ and $A_{\mathrm{GM}}$ apart result in a less strin- gent helium-heat paradox as well? Or are changes in the effective mixing rate over the range of potential $A_{\text {Redi }}$ too small to make a difference?

\section{Model description and experimental setup}

The physical climate model used here is described in Galbraith et al. (2011) and is a lower-resolution version of the CM2M model of Dunne et al. (2012). The atmosphere has a horizontal resolution of $3.75^{\circ} \times 3^{\circ}$ in the horizontal and has 24 levels in the vertical, with a topmost level at $3 \mathrm{mb}$ and 4 layers in the bottom $100 \mathrm{mb}$ to represent the surface boundary layer. The finite-volume core atmosphere model contains up-to-date parameterizations of gravity wave drag, clouds and radiation (the last of which has a diurnal cycle). The ocean has a nominal horizontal resolution of $3^{\circ} \times 2^{\circ}$, with enhanced zonal resolution near the Equator so as to resolve the equatorial waveguide. In the vertical the resolution is $10 \mathrm{~m}$ over the top $100 \mathrm{~m}$, increasing to $494 \mathrm{~m}$ at level 28 , the bottom-most box. The ocean model is run with $A_{\mathrm{GM}}$ spatially varying as in Gnanadesikan et al. (2006) ranging between 200 and $1400 \mathrm{~m}^{2} \mathrm{~s}^{-1}$ depending on the shear between 100 and $2000 \mathrm{~m}$ depth. As $A_{\mathrm{GM}} \times S$ defines a streamfunction for overturning that can become unrealistically large when slopes become infinite within the mixed layer, a maximum of $A_{\mathrm{GM}} \times S_{\mathrm{max}}$ is applied with $S_{\mathrm{max}}=0.01$. The coefficient $A_{\text {Redi }}$ by contrast is held fixed over time. For the control version of the model a spatially constant value of $800 \mathrm{~m}^{2} \mathrm{~s}^{-1}$ was used.

The model was initialized with modern ocean temperatures and salinities and with greenhouse gasses and solar radiation fixed at 1860 levels. A 1500 -year spinup was then performed, at which point three additional runs, with $A_{\text {redi }}=400,1200$, and $2400 \mathrm{~m}^{2} \mathrm{~s}^{-1}$, were spun off the main trunk and, along with the control, run for 1000 years. We will denote the runs by the $A_{\text {Redi }}$ coefficient as AREDI400, AREDI800, AREDI1200 and AREDI2400. Results are shown from the final century of these simulations.

An additional simulation, denoted ABER2D, sets $A_{\text {Redi }}$ to the value calculated by Abernathey and Marshall (2013) for the surface layer that is shown in Fig. 2c. As is the case for all the other runs, this value is taken to be isotropic and depth-invariant. Neither assumption is likely to hold in the real world. The runs here should therefore be taken as a first step towards implementing a more realistic parameterization of $A_{\text {Redi }}$. This simulation was also initialized from the control at year 1500 of the spinup and run for 500 years.

A number of biogeochemical tracer packages were run in our version of ESM2Mc. We will discuss in particular the Biology, Light, Iron, Nutrients and Gasses (BLING) model described in Galbraith et al. (2010), which solves for macronutrient and micronutrient cycling using a mechanistic, but highly parameterized biology. The original version of BLING carried four tracers, phosphate, dissolved organic 
matter, iron and oxygen. The iron, phosphate and available light were used to calculate a growth rate, which in turn was used to diagnose biomass, grazing and uptake using a quasi-equilibrium assumption. The resulting model produces nutrient, chlorophyll (Galbraith et al., 2010) and oxygen (Gnanadesikan et al., 2013) fields comparable to those achieved with models with much more complicated representations of ecosystems. The version of BLING used in Galbraith et al. (2011) added carbon and radiocarbon cycling, finding that ESM2Mc produces a reasonable distribution of radiocarbon as well.

Additionally, simulations of mantle He based on the work of Dutay et al. (2004) were run. In the original protocol ${ }^{3} \mathrm{He}$ and ${ }^{4} \mathrm{He}$ are fixed in the atmosphere at prebomb levels and emitted from the ocean bottom along ridges. Following the work of Farley et al. (1995), injection is taken as proportional to the spreading rate and occurs at a depth approximately $300 \mathrm{~m}$ above the ridge axis. In the original OCMIP2 (Ocean Carbon-Cycle Model Intercomparison Project Phase 2) protocol (Dutay et al., 2004) the total ${ }^{3} \mathrm{He}$ emission was normalized to give a global value of 1070 mol year $^{-1}$ (Craig et al., 1975) and no temperature anomaly was associated with the helium flux. Based on the work of Bianchi et al. (2010) this value was scaled down to 527 mol year $^{-1}$. CM2Mc also includes a geothermal heat flux which varies from a value of around $50 \mathrm{~mW} \mathrm{~m}^{-2}$ in the abyssal plains to peak values slightly above $100 \mathrm{~mW} \mathrm{~m}^{-2}$ in the East Pacific Rise with a total heat flux to the ocean of about 23TW. Both the bottom heat and $\mathrm{He}$ fluxes are held constant with time.

Spinup is an issue with coupled models. As described in Pradal and Gnanadesikan (2014) the surface temperatures are close to equilibrium after a few hundred years. This may not be the case for the deep ocean however, as the timescale for equilibrating radiocarbon can be many thousands of years, far longer than the spinups used in the majority of coupled climate models (which are generally from a few hundred to a few thousand years). Caution should thus be used in interpreting mean results. Since the models are initialized from observations, changes which enhance errors are likely to be significant, while it is possible that changes in diffusion which seem to reduce errors may in fact produce an overshoot in the opposite direction after many thousands of years. The key metrics which we use here, in particular the relationships between helium and radiocarbon and the sharpness of the plumes, adjust much more rapidly, with a timescale of about 100 years. This can be seen by comparing the results in this version of the manuscript with the discussion paper, where results were presented after 500 years of simulation.

\section{Results}

\subsection{Mean hydrography}

The coarse-resolution Earth system models do a reasonable job at reproducing the large-scale hydrography of the ocean. Figure $4 \mathrm{a}$ shows the horizontally averaged temperature in the models. The horizontal axis is cut off at $12^{\circ} \mathrm{C}$ (corresponding to a depth of around $200 \mathrm{~m}$ ) in order to highlight the differences at depth. The relative lack of sensitivity of the mean thermocline to changes in $A_{\text {Redi }}$ stands in strong contrast to $A_{\mathrm{GM}}$, which plays a major role in setting temperatures at these depths (Danabasoglu et al., 1994; Gnanadesikan, 1999). In the deep ocean, there is a general tendency for the models with higher levels of mixing to produce more realistic cold temperatures.

Salinity (Fig. 4b) shows a quite different behavior. The observed mean salinity profile is low at the ocean surface as a result of fresh mixed layers at high latitudes, it exhibits a subsurface maximum associated with the subtropical gyres and a subsurface minimum associated with the formation of mode and intermediate waters. The lowest mixing case (AREDI400, black line) tends to overestimate the strength of polar haloclines, while the higher mixing cases (AREDI1200, AREDI2400 and ABER2D) all capture the near-surface salinity maximum while erasing vertical gradients in salinity below about $1000 \mathrm{~m}$. The AREDI800 simulation does a good job of capturing the deeper salinity structure but less of a good job near the surface. Together the temperature and salinity plots illustrate the difficulties in "tuning" Earth system models - parameterizations that improve one field may not improve another.

Radiocarbon (Fig. 4c) is generally too high in the models, both at the surface and at depth. This suggests that either our rates of air-sea exchange, vertical exchange (due to advection and diffusion), or both are too vigorous. In general, increasing mixing tends to increase radiocarbon in the deep ocean, though the intramodel differences are generally smaller than the model-observation differences. To firstorder, the average depletion in the deep ocean is within about $15 \%$ of observations, implying an error in radiocarbon age of around 120 years.

Helium isotope anomalies (Fig. 4d) are also too large in the deep ocean (implying too little ventilation in contrast to radiocarbon). As expected, increasing $A_{\text {Redi }}$ tends to reduce the deep isotope anomaly. Also as expected, the relative change appears to be much larger for helium than it is for radiocarbon. While the deep overprediction of mantle helium is striking, the total mantle helium inventory is less sensitive, with the average value for AREDI400 of $13.2 \%$ and AREDI2400 of $9.3 \%$ bracketing the observed value of $11.1 \%$. The models capture most of the observed horizontally averaged $\delta^{3} \mathrm{He}$ signal. 


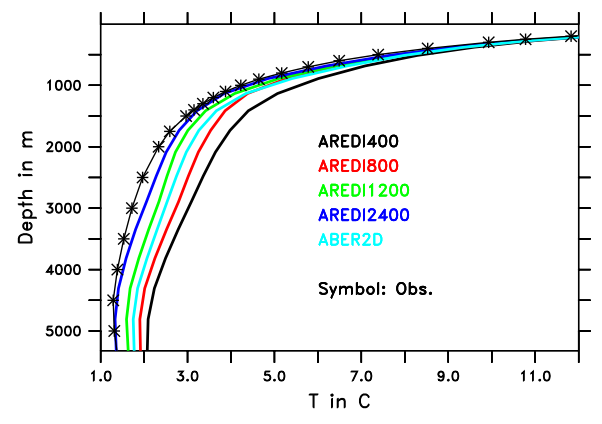

(a) Temperature

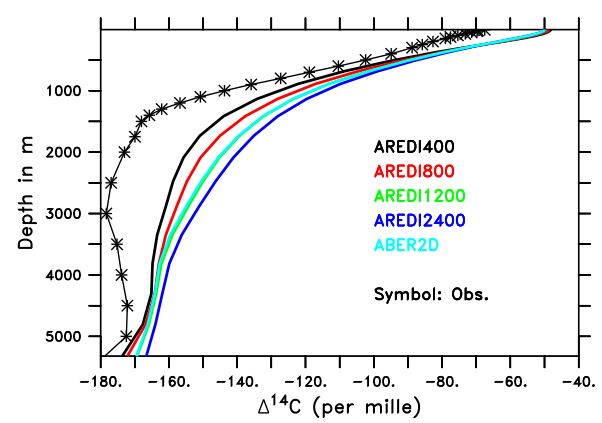

(C) Preindustrial radiocarbon

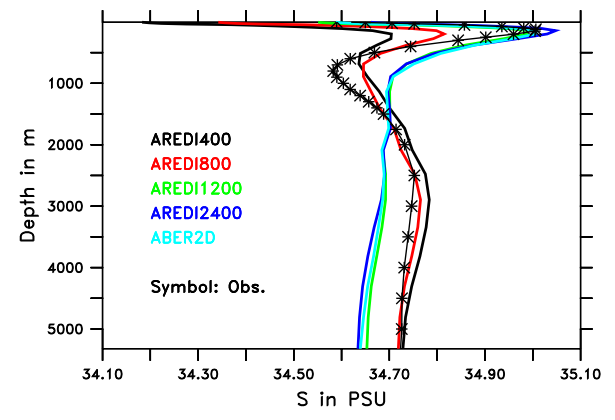

(B) Salinity

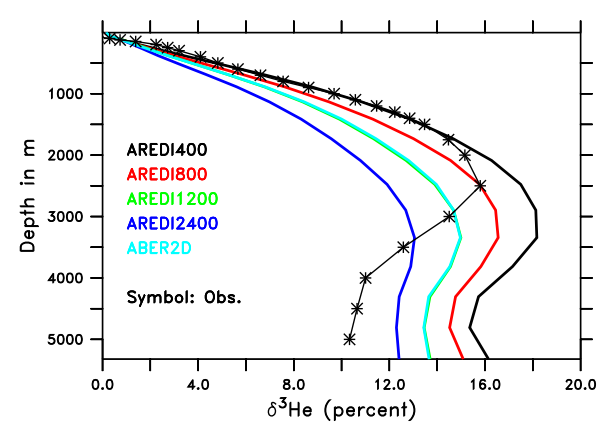

(D) Helium-3

Figure 4. Mean hydrography in the Earth system model suite. (a) Temperature, compared with the World Ocean Atlas. (b) Salinity compared with the World Ocean Atlas. (c) Radiocarbon, compared with Key et al. (2004). (d) Helium isotope anomaly compared with Bianchi et al. (2010).

\subsection{Ventilation in the model suite}

As discussed in Pradal and Gnanadesikan (2014), increasing $A_{\text {Redi }}$ results in destabilizing the high-latitude Southern Ocean and North Pacific. Models with more intense eddy mixing stir more salt into the high-latitude surface layer. This reduces the salinity contrast across the winter halocline, which is the dominant factor in determining vertical exchange in the subpolar North Pacific and Southern Ocean. The results of this can be seen in Fig. 5. The AREDI400 simulation with the lowest mixing captures the value of the minimum in radiocarbon in the North Pacific, though the depth at which this minimum is seen is too great. As $A_{\text {Redi }}$ increases the result is to bring more young water down in the North Pacific, reducing the correlation between the observed and modeled zonal mean from 0.88 (AREDI400) to 0.71 (AREDI2400), and substantially increasing the RMSE (root mean squared error) in radiocarbon concentration from 22 (AREDI400) to $42 \%$ (AREDI2400). The Abernathey and Marshall (2013) spatially varying diffusion tends to act like low diffusion in the south, but higher diffusion in the north, and so also produces enhanced, unrealistic northern sinking, though not to the same extent as the AREDI2400 case. The differences between the AREDI400 and AREDI800 runs are largely due to an increase in the gradient between the Southern Ocean and the North Pacific, with the Southern Ocean values of radiocarbon remaining relatively un- changed, suggesting that lateral transport is important here. However, the differences between AREDI1200, AREDI2400 and AREDI800 show the impact of decreases in high-latitude stratification (particularly in the North Pacific) as well. In recent work (Gnanadesikan et al., 2015) we show that the destratification of the North Pacific also results in unrealistic uptake of anthropogenic carbon in this region.

Mantle helium shows a behavior somewhat similar to radiocarbon, but with the difference that the highest values are found in the tropical South Pacific rather than in the far north (Fig. 6a). The AREDI400 case largely captures the location of the maximum zonal mean $\delta^{3} \mathrm{He}$ anomaly but, as with radiocarbon, increasing $A_{\text {Redi }}$ results in ventilation that removes mantle helium from the far northern Pacific, decreasing the correlation with observations and raising the mean error. There is, however, some sense that the lower values of $A_{\text {Redi }}$ result in an excessively high peak of mantle helium in the tropics, so that the RMSE in zonally averaged $\delta^{3} \mathrm{He}$ is actually lowest (4.5\%) for the AREDI800 simulation rather than the AREDI400 simulation (5.5\%), despite having a lower correlation coefficient (0.74 vs. 0.78$)$. The ABER2D simulation does less well than the AREDI800 in this case, though the peak value in the South Pacific is somewhat better captured. 


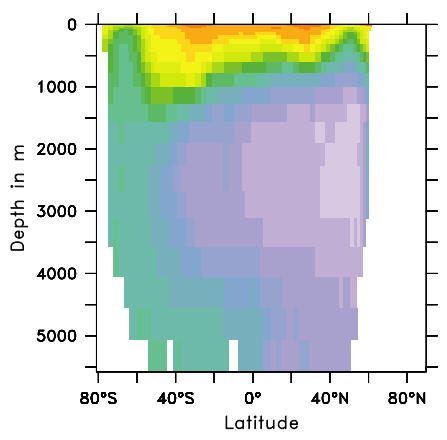

(A) Obs. $\triangle^{14} \mathrm{C}$

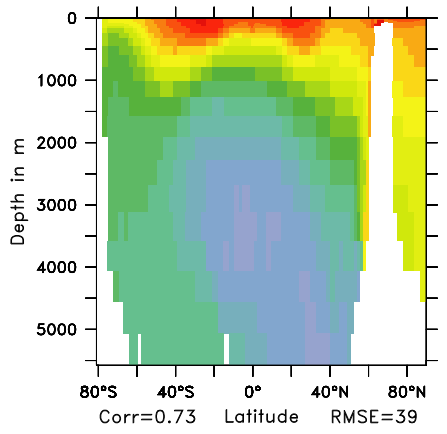

(D) AREDI1 $200 \triangle^{14} \mathrm{C}$

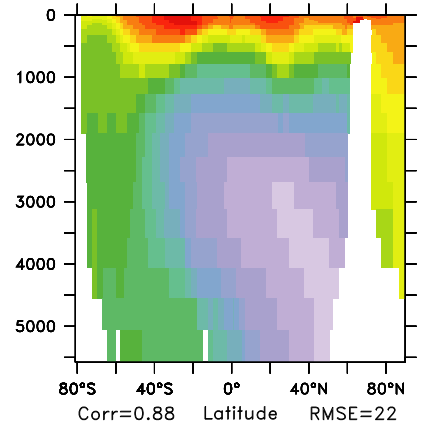

(B) AREDI400 $\triangle^{14} \mathrm{C}$

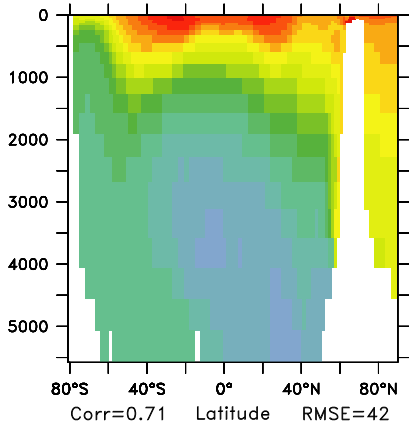

(E) AREDI2400 $\Delta^{14} \mathrm{C}$

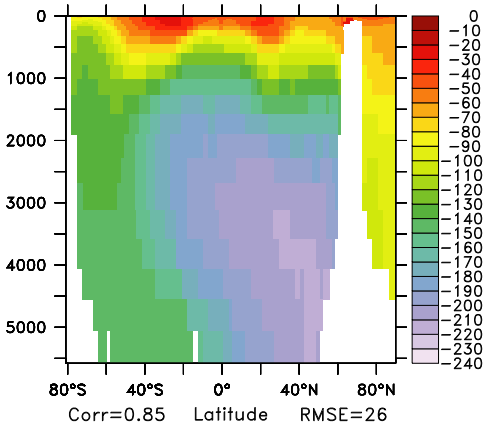

(C) AREDI800 $\triangle^{14} \mathrm{C}$

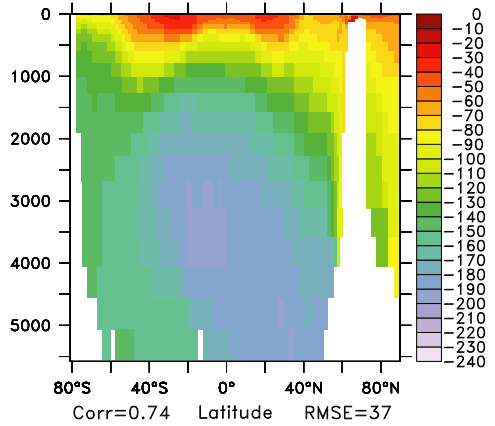

(F) ABER2D $\triangle^{14} \mathrm{C}$

Figure 5. Zonally averaged $\Delta^{14} \mathrm{C}$ (in \%o) in the Pacific. (a) From the observational data set of Key et al. (2004). (b) AREDI400. (c) AREDI800 (d) AREDI1200 (e) AREDI2400 (f) ABER2D.

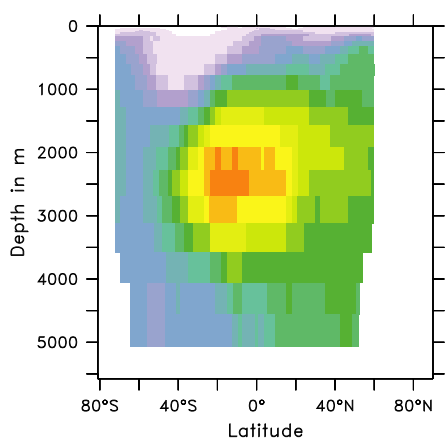

(A) Obs. $\delta^{3} \mathrm{He}$

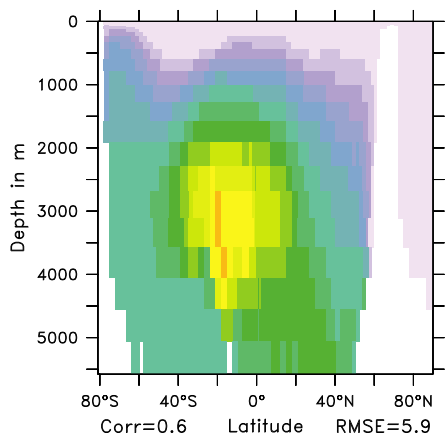

(D) AREDI1 $200 \delta^{3} \mathrm{He}$

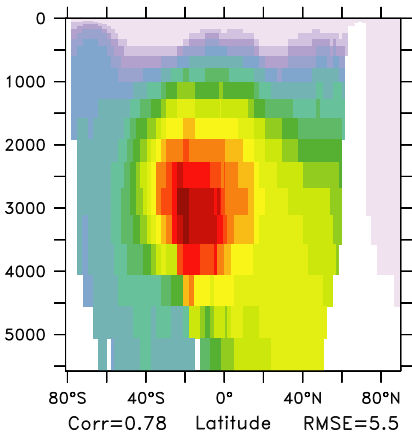

(B) AREDI400 $\delta^{3} \mathrm{He}$

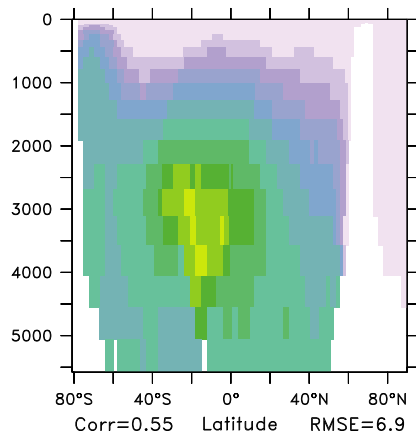

(E) AREDI2400 $\delta^{3} \mathrm{He}$

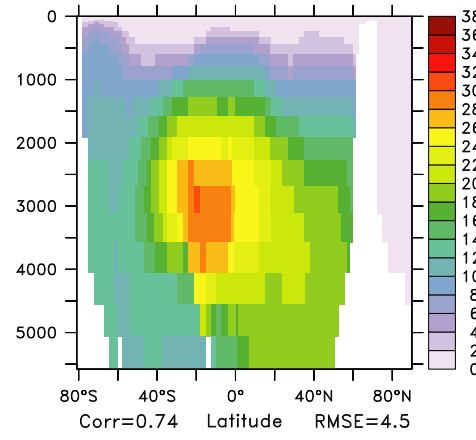

(C) AREDI800 $\delta^{3} \mathrm{He}$

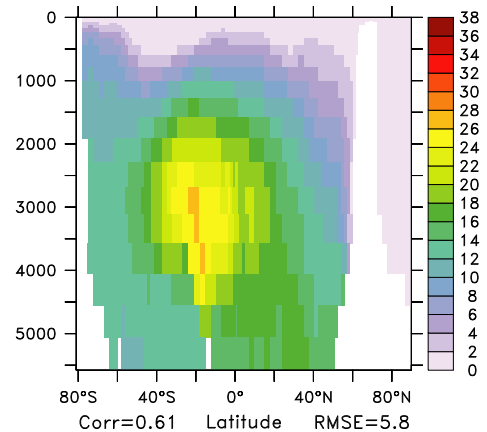

(F) ABER2D $\delta^{3} \mathrm{He}$

Figure 6. Zonally averaged $\delta^{3} \mathrm{He}$ in (\%) in the Pacific. (a) From the observational data set of Bianchi et al. (2010). (b) AREDI400. (c) AREDI800 (d) AREDI1200 (e) AREDI2400 (f) ABER2D. 


\subsection{Radiocarbon vs. mantle helium}

The changes in deep tracers are reflected in changes in the scatterplot of deep $\delta^{3} \mathrm{He}$ vs. $\Delta^{14} \mathrm{C}$ (Fig. 7). As the mixing increases, the peak seen in the southeastern Pacific becomes smoothed out and the maximum depletion decreases. However, all five runs lie close to the observed relationship. Since the $\delta^{3} \mathrm{He}$ values are linear in the source term, it is easy to see that doubling this term to the value of Craig et al. (1975) will lead to a strong offset. The results of Bianchi et al. (2010) appear to be robust against changes in $A_{\text {Redi }}$ that are not directly associated with changes in $A_{\mathrm{GM}}$. Resolving the isopycnal mixing paradox thus does not affect the helium-heat paradox.

This result is contrary to what might be expected from the changes in the tracers seen in Figs. 5 and 6, which show clear changes in the extreme values of these tracers in the deep ocean and substantially greater penetration of young waters as $A_{\text {Redi }}$ increases. However, these changes in the endpoints do not substantially change the effective rate at which tracer signals make their way from the deep ocean to the surface. Our results thus suggest that the key barrier to transfer between the deep ocean and the surface is not mixing across the mixed layer base but transport from the ocean interior to the high-latitude regions. Such transport is accomplished both by advection and turbulent diffusion. If one considers a Péclet number for the deep South Pacific $U L / A_{\text {Redi }}$, deep velocities $U$ are on the order of $1 \mathrm{~mm} \mathrm{~s}^{-1}$ but the length scale $L$ between where $\mathrm{He}$ is injected and where isopycnals reach the surface is on the order of $4000 \mathrm{~km}$. Thus, even for the highest value of $A_{\text {Redi }}$, the Péclet number is greater than 1 and advection dominates mixing.

Examination of changes in overturning supports this idea. We can define the overturning as

$M_{\text {over }}=\int_{z_{1}}^{z_{2}} \int_{x_{w}}^{x_{e}} v \times \mathrm{d} x \times \mathrm{d} z$,

where $v$ is the northward velocity, and $x_{w}, x_{e}, z_{1}$ and $z_{2}$ are the limits of integration in the west, east, and vertical directions. The integral is taken at $30^{\circ} \mathrm{S}$ in the Pacific. If the integral is performed relative to the surface $\left(z_{1}=z, z_{2}=0\right.$, Fig. 8a) the similarity in the northward transport of surface water is emphasized, but differences appear in the deep ocean. Note that the value does not go to zero at the bottom because water that flows into the southern Pacific leaves through the Indonesian throughflow and Bering straits. This net flux does change as $A_{\text {Redi }}$ changes. Summing the northward transport from the bottom of the ocean upward $\left(z_{1}=\right.$ $H, z_{2}=z$ where $H$ is the ocean depth, Fig. 8b), we see that the models with constant $A_{\text {Redi }}$ all have similar inflows of deep water of around $10 \mathrm{~Sv}$ (only the ABER2D simulation is noticeably lower). The main thing that changes between the simulations is whether this water is largely returned below the thermocline (as happens for the higher mixing cases) or whether some small fraction of it upwells into the tropical thermocline and is returned through the Indonesian throughflow (as appears to be the case for AREDI400). From the point of view of flushing the deep tropical Pacific, however, it is largely irrelevant which pathway is taken. Instead, what matters is the throughflow, which is relatively constant across the different models.

\subsection{The southeastern Pacific $\delta^{3} \mathrm{He}$ plume}

Both the models and observations show high values in the southeastern Pacific, where a rapidly spreading rift releases large amounts of mantle helium. The sharpness of this plume, however, varies substantially between the models. In Fig. 9, the distributions at $2500 \mathrm{~m}$ are overlaid with the actual observations between 2250 and $2750 \mathrm{~m}$ (filled squares). Differences in color thus highlight locations where the model is mismatched with the in situ observations. In Fig. 9a we see that there are some differences between the gridded and in situ observations. This reflects the fact that in order to extrapolate over the relatively coarse observations in the deep ocean to a global data set, Bianchi et al. (2010) had to define a radius of influence that effectively smooths the data and may be comparable to the size of some of the features seen in the model output. For this reason, we have not chosen to present RMSEs, as these would imply a greater degree of precision than is justified given the coarseness of the sampling and the model.

However, even a qualitative comparison makes it clear that the mixing exerts a strong control over how well the models match the observations. In the AREDI400 run (Fig. 9b), the symbols over the East Pacific Rise show up as lower than the model, which produces a peak value exceeding $70 \%$, while the highest values in the observations are around $45 \%$. By contrast, the AREDI2400 model produces no values higher than $36 \%$. The AREDI800, AREDI1200 and ABER2D models all produce peaks that are qualitatively similar to observations.

This is not merely the impact of the depth chosen. Figure 10 shows a depth-longitude section of $\delta^{3} \mathrm{He}$ cutting through the center of the plume between latitudes of 20 and $30^{\circ} \mathrm{S}$. Again, we see that the observations over the ridge show up as too low in the AREDI400 run, too high in the AREDI2400 run and close to the simulated values for the AREDI800, AREDI1200 and ABER2D simulations (though note that the highest values in the models are displaced downwards relative to observations). This suggests that very low diffusion coefficients in the deep southeastern Pacific are not consistent with the release of helium there, in contrast to current theory. The values that are most consistent with the observations are comparable to what is found nearer to the surface. This suggests that the isopycnal mixing paradox is not simply a matter of $A_{\text {Redi }}$ being much larger than $A_{\mathrm{GM}}$ in the surface layer but also in the deep ocean. 


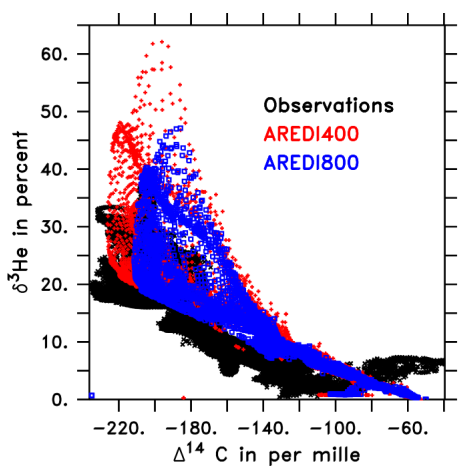

(A) $\delta^{3} \mathrm{He}$ vs. $\Delta^{14} \mathrm{C}$

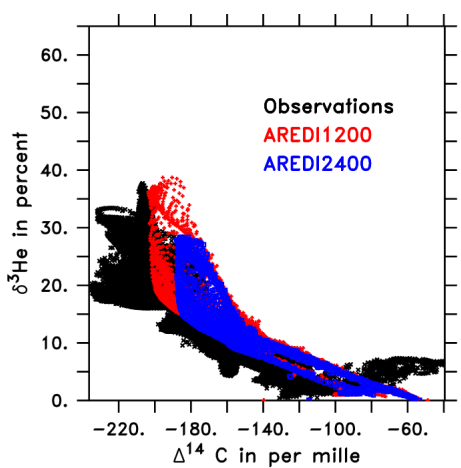

(B) $\delta^{3} \mathrm{He}$ vs. $\Delta^{14} \mathrm{C}$

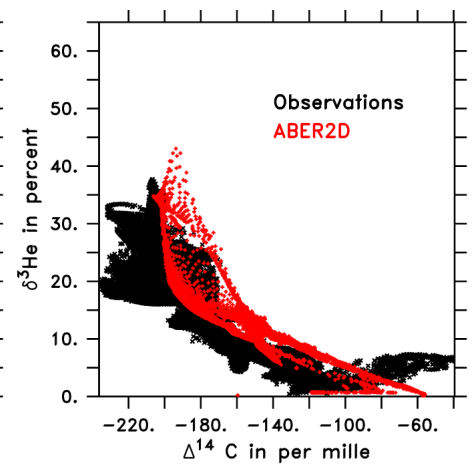

(C) $\delta^{3} \mathrm{He}$ vs. $\Delta^{14} \mathrm{C}$

Figure 7. Scatterplots of $\delta^{3} \mathrm{He}$ vs. $\Delta^{14} \mathrm{C}$ for different values of $A_{\text {Redi. }}$ On all plots observations are in black. (a) AREDI400 (red) and AREDI800 (blue). (b) AREDI1200 (red) and AREDI2400 (blue) (c) ABER2D (red).

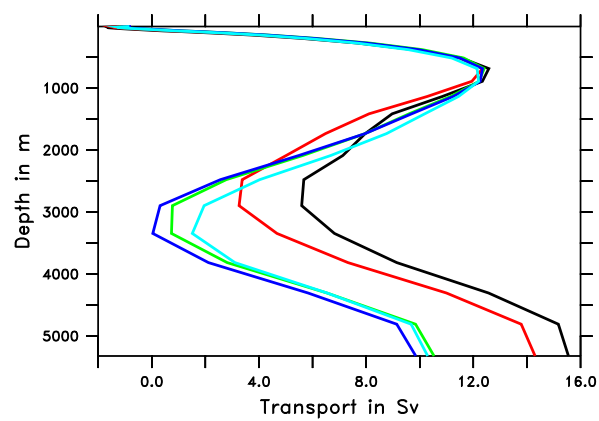

(A) Overturn from Top

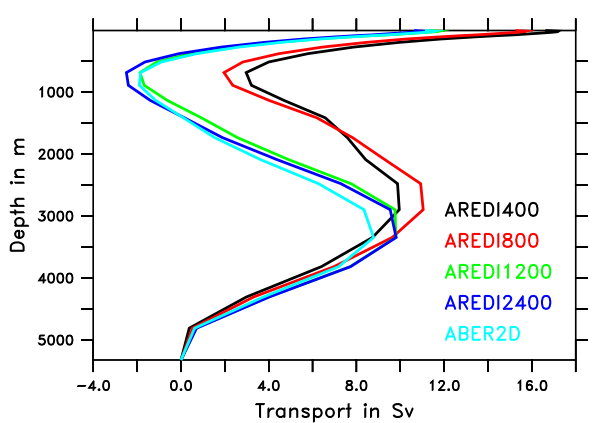

(B) Overturn from Bottom

Figure 8. Overturning in the South Pacific at a latitude of $30^{\circ} \mathrm{S}$ across the different model runs. Overturning is computed as a running sum of northward transport. (a) Overturning summed from top to bottom, emphasizing similarity in northward surface flow. (b) Overturning summed from bottom to top, emphasizing similarity in deep inflow of Antarctic Bottom Water.

\section{Conclusions}

Our simulations of helium isotopes and radiocarbon have not resolved either of the two paradoxes outlined earlier in the paper. While larger values of isopycnal mixing varying independently of $A_{\mathrm{GM}}$ do allow for more exchange between the surface and deep ocean, this exchange does not change the fundamental relationship between radiocarbon and helium isotopes in the deep ocean. Isopycnal mixing does not offer a solution to the helium paradox. Moreover, the distribution of helium isotopes in the abyssal ocean do not support the idea that values of $A_{\text {Redi }}$ below the thermocline must be much smaller than values at the surface, as found in the NCAR CESM model. Nor do they support the idea that the coefficients must be much smaller than the values of $A_{\mathrm{GM}}$ found in boundary currents where isopycnal slopes are much larger, as found in models such as GFDL's ESM2G. Instead, relatively large values of $A_{\text {Redi }}$ are needed to produce sufficiently diffuse plumes.

Resolving the helium paradox is beyond both the scope of this paper and the expertise of the authors. However, we can comment on the isopycnal mixing paradox. Recall that this paradox stems from three assumptions - equivalence of $A_{\mathrm{GM}}$ and $A_{\text {Redi }}$, a strong relationship between $A_{\mathrm{GM}}$ and baroclinicity, and limits on the maximum value of $A_{\mathrm{GM}}$. While the last two of these appear to be well founded in theory and modeling, it is not at all clear that $A_{\mathrm{GM}}$ should equal $A_{\text {Redi }}$. Indeed, recently published estimates of $A_{\mathrm{GM}}$ and $A_{\text {Redi }}$ based on theory (Smith and Marshall, 2009; Vollmer and Eden, 2013) and simulation (Abernathey et al., 2013) show different values for the two coefficients. Our results here support the idea that breaking this equivalence allows for more realistic tracer distributions in many parts of the ocean, particularly in the abyssal South Pacific. The reasons why this equivalence breaks down are less clear but likely have to do with the fact that anomalies in layer height can be tightly connected to anomalies in velocity, and that viscous forces act to smooth out such variations in ways that they do not act to smooth out variations in passive tracers.

These simulations highlight the utility of passive tracers in constraining climate models. Passive tracers can reveal when improvements in physical fields are occurring for the wrong reasons. As discussed in Pradal and Gnanadesikan (2014), the changes produced by increasing $A_{\text {Redi }}$ act to reduce er- 


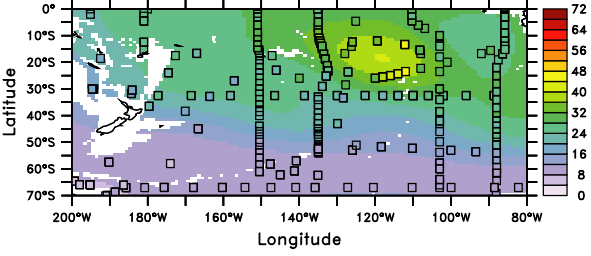

(A) $\delta^{3} \mathrm{He}$ Obs

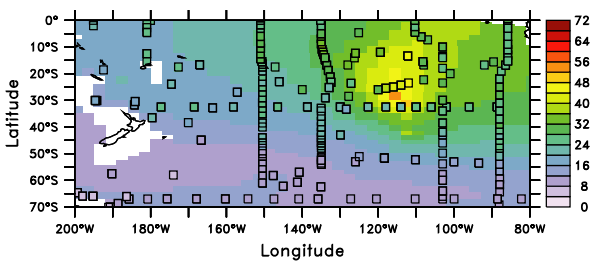

(C) $\delta^{3} \mathrm{He}$ AREDI800

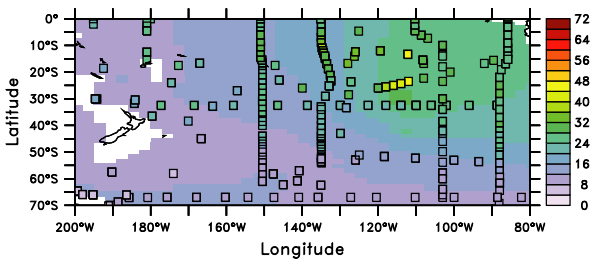

(E) $\delta^{3} \mathrm{He}$ AREDI2400

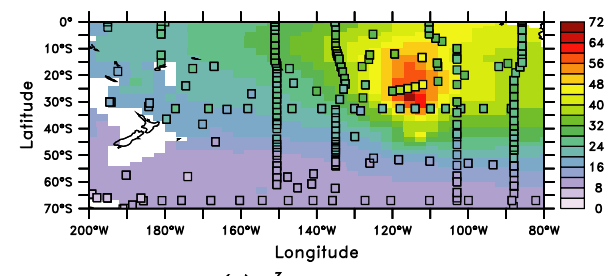

(B) $\delta^{3} \mathrm{He}$ AREDI400

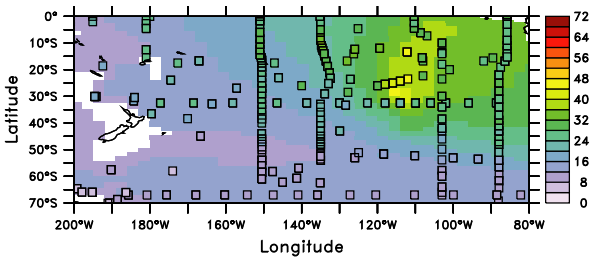

(D) $\delta^{3} \mathrm{He}$ AREDI 1200

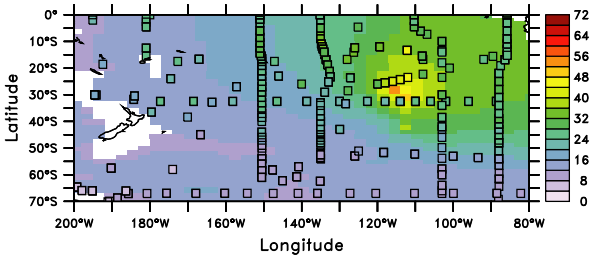

(F) $\delta^{3} \mathrm{He}$ ABER2D

Figure 9. $\delta^{3} \mathrm{He}$ (in \%) in the SE Pacific between the depths of 2250 and $2750 \mathrm{~m}$. Symbols are taken from observational data set of Bianchi et al. (2010). (a) Gridded data set of Bianchi et al. (2010) showing effects of smoothing. (b) AREDI400. (c) AREDI800. (d) AREDI1200. (e) AREDI2400. (f) ABER2D.

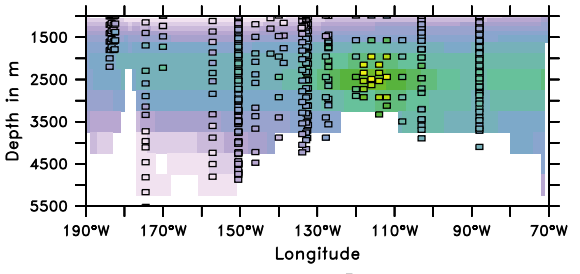

(A) $20-30 \mathrm{~S} \delta^{3} \mathrm{He}$ Obs.

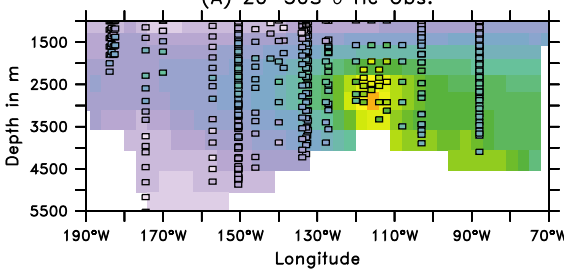

(C) $20-30 \mathrm{~S} \delta^{3} \mathrm{He} \mathrm{A}_{\text {redi }}=800$

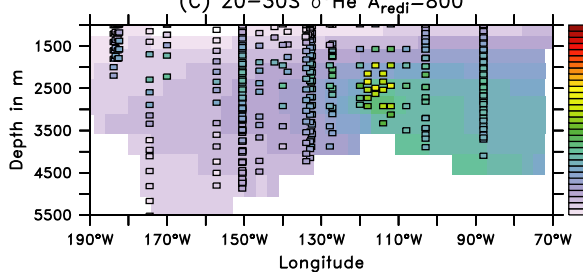

(E) $20-30 \mathrm{~S} \delta^{3} \mathrm{He} \mathrm{A}_{\mathrm{redi}}=2400$

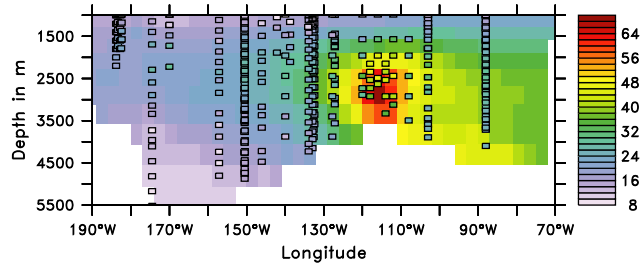

(B) $20-30 \mathrm{~S} \delta^{3} \mathrm{He} \mathrm{A}_{\text {redi }}=400$

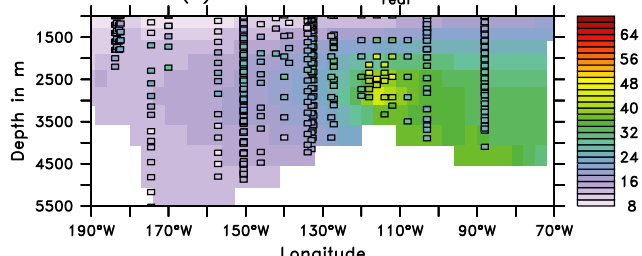

(D) $20-30 \mathrm{~S} \delta^{3} \mathrm{He} \mathrm{A}_{\text {redi }}=1200$

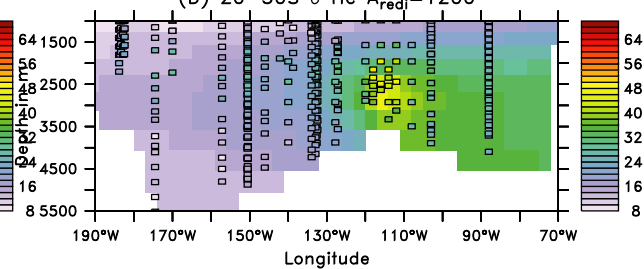

(F) $20-30 \mathrm{~S} \delta^{3} \mathrm{He} A B E R 2 \mathrm{D}$

Figure 10. $\delta^{3} \mathrm{He}$ (in \%) in the SE Pacific between the latitudes of 20 and $30^{\circ} \mathrm{S}$. Symbols are taken from the observational data set of Bianchi et al. (2010). (a) Gridded data set of Bianchi et al. (2010) showing effects of smoothing. (b) AREDI400. (c) AREDI800. (d) AREDI1200. (e) AREDI2400. (f) ABER2D. 
rors in sea surface temperature in the North Pacific, where the baseline model is too cold. Without carefully examining the circulation it would be easy to conclude that this produces a more realistic climate. However, as shown by the radiocarbon, the improvement in sea surface temperature comes at the cost of (unrealistically) increasing deep convection. Additionally, there may be locations (such as the deep South Pacific) where gradients in physical properties along isopycnals are relatively weak but tracer gradients are relatively strong, so that passive tracers act as a better constraint on model physics than traditional physical tracers. Utilizing such tracers, however, requires knowledge about sources and sinks that are not always well-constrained. We suggest that more attention to tracer-tracer relationships, particularly regarding radiocarbon, may be helpful in this regard.

While the results here do support the idea that the isopycnal mixing paradox should be resolved in favor of allowing $A_{\text {Redi }}$ to differ from $A_{\mathrm{GM}}$ and indicate that relatively large values of $A_{\text {Redi }}$ in the ocean interior do not result in breaking the models, more work is clearly needed to find a fully prognostic parameterization. Three areas in particular require more attention.

1. Because coupled models do not necessarily place boundary currents in the right place, fixing $A_{\text {Redi }}$ as we have done here can result in higher impacts of isopycnal mixing in boundary currents than is physically reasonable. This may be one reason that the ABER2D simulation produces too much convection in the North Pacific. Our results support the continued development of models that predict both the length and timescales involved in isopycnal mixing.

2. Our ABER2D results assumed a mixing coefficient that is isotropic. In reality, mixing is probably larger in the zonal or along-flow direction than in the meridional or cross-flow direction. Better constraining of anisotropy in both observations and numerical simulations remains an important task.

3. Our results also assume that $A_{\text {Redi }}$ is constant with depth. Again, both numerical simulations (Abernathey et al., 2013) and limited observational results (Rye et al., 2012) suggest this is unlikely to be the case, with higher values at internal critical layers and lower values in the deep ocean where flow is constrained by topography. More work is needed however, to constrain this vertical dependence, as our results suggest it is unlikely to be simply related to stratification.

The Supplement related to this article is available online at doi:10.5194/os-11-591-2015-supplement.
Acknowledgements. A. Gnanadesikan and M.-A. Pradal were supported under DOE grant DE-SC0007066 and NSF grant EAR-1135382. Support for R. Abernathey was provided by NASA grant NNX14AI46G. We thank Inga Koszalka and Daniele Bianchi for useful discussions, and Matthew Hecht, Scott Reckenger and an anonymous reviewer for constructive suggestions and critiques.

Edited by: M. Hecht

\section{References}

Abernathey, R. and Marshall, J.: Global surface eddy diffusivities derived from satellite altimetry, J. Geophys. Res.-Oceans, 118, 901-916, 2013.

Abernathey, R., Marshall, J., Shuckburgh, E., and Mazloff, M.: Enhancement of mesoscale eddy stirring at steering levels in the Southern Ocean, J. Phys. Oceanogr., 40, 170-185, 2010.

Abernathey, R., Ferreira, D., and Klocker, A.: Diagnostics of isopycnal mixing in a circumpolar channel, Ocean Model., 72, 1-16, 2013.

Anderson, D.: The helium paradoxes, P. Natl. Acad. Sci. USA, 95, 4822-4827, 1998.

Bachman, S., Fox-Kemper, B., and Bryan, F. C.: A tracerbased inversion method for diagnosing eddy-induced diffusivity and advection. Ocean Model., 86, 1-14, doi:10.1016/j.ocemod.2014.11.006, 2015.

Bauer, S., Swenson, M. S., Griffa, A., Mariano, A. J., and Owens, K.: Eddy-mean flow decomposition and eddy-diffusivity estimates in the tropical Pacific Ocean, 1. Methodology, J. Geophys. Res., 103, 30855-30871. 1998.

Baynte, D., Visbeck, M., Tanhua, T., Krahmann, G., and Karstensen, J.: Lateral diffusivity from tracer release experiments in the tropical thermocline, J. Geophys. Res.-Oceans, 118, 27192733, 2013.

Bentsen, M., Bethke, I., Debernard, J. B., Iversen, T., Kirkevåg, A., Seland, Ø., Drange, H., Roelandt, C., Seierstad, I. A., Hoose, C., and Kristjánsson, J. E.: The Norwegian Earth System Model, NorESM1-M - Part 1: Description and basic evaluation of the physical climate, Geosci. Model Dev., 6, 687-720, doi:10.5194/gmd-6-687-2013, 2013.

Bianchi, D., Sarmiento, J. L., Gnanadesikan, A., Key, R. M., Schlosser, P., and Newton, R.: Low helium flux from the mantle inferred from simulations of oceanic helium isotope data, Earth Planet. Sc. Lett., 297, 379-386, doi:10.1016/j.eps1.2010.06.037, 2010.

Craig, H., Clarke, W. B., and Beg, M. A.: Excess ${ }^{3}$ He in deep water on the East Pacific rise, Earth Planet. Sc. Lett., 26, 125-132, 1975.

Danabasoglu, G., McWilliams, J. C., and Gent, P.: The role of mesoscale tracer transports in the global ocean circulation, Science, 264, 1123-1126, 1994.

Danabasoglu, G., Bates, S. C., Brieglieb, B. P., Jayne, S. R., Jochum, M., Large, W. G., Peacock, S., and Yeager, S. G.: The CCSM4 ocean component, J. Climate, 25, 1361-1389, 2012.

Dunne, J. P., John, J. G., Adcroft, A. J., Griffies, S. M., Hallberg, R. W., Shevliakova, E. N., Stouffer, R. J., Cooke, W., Dunne, K. A., Harrison, M. J., Krasting, J. P., Levy, H.,Malyshev, S. L., Milly, P. C. D., Phillips, P. J., 
Sentman, L. A., Samuels, B. L., Spelman, M. J., Winton, M.,Wittenberg, A. T., and Zadeh, N.: GFDL's ESM2 global coupled climate-carbon Earth System Models Part I: Physical formulation and baseline simulation characteristics, J. Climate, 25, 6646-6665, 2012.

Dutay, J.-C., Jean-Baptiste, P., Campin, J.-M., Ishida, A., MaierReimer, E., Matear, R. J., Mouchet, A., Totterdell, I. J., Yamanaka, Y., Rodgers, K., Madec, G., and Orr, J. C.: Evaluation of OCMIP-2 ocean models' deep circulation with mantle helium-3, J. Marine Syst., 48, 15-36, 2004.

Eady, E.: Long waves and cyclone waves, Tellus, 1, 33-52, 1949.

Emerson, S. and Hedges, J. I.: Chemical Oceanography and the Marine Carbon Cycle, Cambridge Univ. Press, New York, 2008.

Farley, K. A., Maier-Reimer, E., Schlosser, P., and Broecker, W. S.: Constraints on mantle He-3 fluxes and deep-sea circulation from an ocean general circulation model, J. Geophys. Res., 100, 38293839, 1995.

Fogli, P., Manzini, E., Vichi, M., Alessandri, A., Patara, L., Gualdi, S., Scoccimoarro, E., Masina, S., and Navarra, A.: INGVCMCC Carbon (ICC): a carbon cycle earth system model, Technical Rep. 61, Centro Euro-Mediterraneo per i Cambiamenti Climatici, Bologna, 2009.

Fox-Kemper, B, Lumpkin, R., and Bryan, F. O.: Lateral transport in the ocean interior, in: Ocean Circulation and Climate - Observing and Modelling the Global Ocean, edited by: Siedler, G., Church, J., Gould, J., and Griffies, S., Elsevier, New York, 2012.

Galbraith, E. D., Gnanadesikan, A., Dunne, J. P., and Hiscock, M. R.: Regional impacts of iron-light colimitation in a global biogeochemical model, Biogeosciences, 7, 1043-1064, doi:10.5194/bg-7-1043-2010, 2010.

Galbraith, E. D., Kwon, E.-Y., Gnanadesikan, A., Rodgers, K. B., Griffies, S. M., Bianchi, D., Dunne, J. P., Sarmiento, J. L., Simeon, J., Slater, R. D., Wittenberg, A. T., and Held, I. M.: Climate variability and radiocarbon in the CM2Mc Earth System Model, J. Climate, 24, 4230-4254, doi:10.1175/2011JCLI3919.1, 2011.

Gent, P. and McWilliams, J. C.: Isopycnal mixing in ocean models, J. Phys. Oceanogr., 20, 150-155, 1990.

Gnanadesikan, A.: A simple model for the structure of the oceanic pycnocline, Science, 283, 2077-2079, 1999.

Gnanadesikan, A., Dixon, K. W., Griffies, S. M., Balaji, V., Barreiro, M, Beesley, J. A., Cooke, W. F., Delworth, T. L., Gerdes, R., Harrison, M. J., Held, I., Hurlin, W. J., Lee, H. C., Liang, Z., Nong, G., Pacanowski, R. C., Rosati, A., Russell, J. L., Samuels, B. L., Song, Q., Spelman, M. J., Stouffer, R. J., Sweeney, C., Vecchi, G. A., Winton, M., Wittenberg, A. T., Zeng, F., Zhang, R., and Dunne, J. P.: GFDL's CM2 Global coupled climate models: Part II: The baseline ocean simulation, J. Climate, 19, 675-697, 2006.

Gnanadesikan, A., Bianchi, D., and Pradal, M. A.: Critical role for mesoscale eddy diffusion in supplying oxygen to hypoxic ocean waters, Geophys. Res. Lett., 40, 5194-5198, doi:10.1002/grl.50998, 2013.

Gnanadesikan, A., Pradal, M. A., and Abernathey, R. P.: Isopycnal mixing by mesoscale eddies significantly impacts oceanic anthropogenic carbon uptake, Geophys. Res. Lett., 42, 4249-4255, doi:10.1002/2015GL064100, 2015.

Gordon, J., O'Farrell, S., Collier, M., Dix, M., and Rotstayn, L., Kowalczyk, Hirst, T., and Watterson, I.: The CSIRO Mk3.5 Cli- mate model, Tech. Rep. 21, Center for Australian Weather and Climate Research, Melbourne, 2010.

Green, J. S.: Transfer properties of the large-scale eddies and the general circulation of the atmosphere, Q. J. Roy. Meteor. Soc., 96, 157-185, 1970.

Griffies, S. M.: The Gent-McWilliams skew flux, J. Phys. Oceanogr., 28, 831-841, 1998.

Griffies, S. M., Gnanadesikan, A., Pacanowski, R. C., Larichev, V. D., Dukowicz, J. K., and Smith, R. D.: Isoneutral diffusion in a $z$-coordinate ocean model, J. Phys. Oceanogr., 28, 805-830, 1998.

Harrison, D. and Ballentine, C. J.: Noble gas models of mantle structure and reservoir mass transfer, Earth's Deep Mantle: structure, composition and evolution, Geophys. Monogr. Ser., 160, 926, 2003.

Jones, C. D., Hughes, J. K., Bellouin, N., Hardiman, S. C., Jones, G. S., Knight, J., Liddicoat, S., O'Connor, F. M., Andres, R. J., Bell, C., Boo, K.-O., Bozzo, A., Butchart, N., Cadule, P., Corbin, K. D., Doutriaux-Boucher, M., Friedlingstein, P., Gornall, J., Gray, L., Halloran, P. R., Hurtt, G., Ingram, W. J., Lamarque, J.-F., Law, R. M., Meinshausen, M., Osprey, S., Palin, E. J., Parsons Chini, L., Raddatz, T., Sanderson, M. G., Sellar, A. A., Schurer, A., Valdes, P., Wood, N., Woodward, S., Yoshioka, M., and Zerroukat, M.: The HadGEM2-ES implementation of CMIP5 centennial simulations, Geosci. Model Dev., 4, 543-570, doi:10.5194/gmd-4-543-2011, 2011.

Key, R. M., Kozyr, A., Sabine, C. L., Lee, K., Wanninkhof, R., Bullister, J., Feely, R. A., Millero, F., Mordy, C., and Peng. T.-H.: A global ocean carbon climatology: results from GLODAP, Global Biogeochem. Cy., 18, GB4031, doi:10.1029/2004GB002247, 2004.

Khatiawala, S., Primeau, F., and Holzer, M.: Ventilation of the deep ocean constrained with tracer observations and implications for radiocarbon estimates of ideal mean age, Earth Planet. Sc. Lett., 325-326, 116-125, doi:10.1016/j.epsl.2012.01.038, 2012.

Ledwell, J. R. and Watson, A. J.: The Santa Monica Basin tracer experiment: a study of diapycnal and isopycnal mixing, J. Geophys. Res., 103, 214999-215129, 1991.

Ledwell, J. R., Watson, A. J., and Law, C. S.: Mixing of a tracer in the pycnocline, J. Geophys. Res., 103, 21499-21529, 1998.

Marshall, J., Shuckburgh, E., Jones, H., and Hill, C.: Estimates and implications of surface eddy diffusivity in the Southern Ocean derived from tracer transport, J. Phys. Oceanogr., 36, 1806-1821, 2006.

Ollitraut, M. and Colin de Verdiere, A.: SOFAR floats reveal midlatitude intermediate North Atlantic circulation, Part II: An Eulerian statistical view, J. Phys. Oceanogr., 32, 2034-2053, 2002.

O'Nions, R. K. and Oxburgh, E. R.: Heat and helium in the earth, Nature, 306, 429-431, 1983.

Pradal, M.-A. and Gnanadesikan, A.: Impact of isopycnal stirring on global climate in an Earth System Model, J. Adv. Model. Earth Sys., 6, 586-601, doi:10.1002/2013MS000273, 2014.

Reckinger, S. J. and Fox-Kemper, B.: Anisotropic mesoscale eddy transport in ocean general circulation models, in preparation, 2015.

Redi, M. H.: Ocean isopycnal mixing by coordinate rotation, J. Phys. Oceanogr., 12, 1154-1157, 1982.

Rye, C. D., Messais, M.-J., Ledwell, J. R., Watson, A. J., Brousseau, A., and King, B. A.: Diapycnal diffusivities 
from a tracer release experiment in the deep sea integrated over 13 years, Geophys. Res. Lett., 39, L04603, doi:10.1029/2011GL050294, 2012.

Rypina, I., Kamenkovich, I., Berloff, P., and Pratt, L.: Eddyinduced particle dispersion in the near-surface Atlantic, J. Phys. Oceanogr., 42, 2206-2228, 2012.

Salas y Mélia D., Chauvin, F., Déqué M., Douville, H., Guérémy J. F., Marquet, P., Planton, S., Royer, J. F., and Tyteca, S.: Description and validation of CNRM-CM3 global coupled climate model, Note de centre GMGEC (internal publication), CNRM, Toulouse, 103, 2005.

Shuckburgh, E. and Haynes, P.: Diagnosing transport and mixing using a tracer-based coordinate system, Phys. Fluids, 15, 33423357, 2003.

Shuckburgh, E., Jones, H., Marshall, J., and Hill, C.: Robustness of effective diffusivity diagnostic in oceanic flows, J. Phys. Oceanogr., 39, 1993-2009, 2009.
Smith, K. S. and Marshall, J.: Evidence for enhanced eddy mixing at mid-depth in the Southern Ocean, J. Phys. Oceanogr., 39, 50 69, 2009.

Turner, G. and Stuart, F., Helium/heat ratios and deposition temperatures of sulphides from the ocean floor, Nature, 357, 581-583, 1992.

Visbeck, M., Marshall, J., Haine, T., and Spall, M.: Specification of eddy transfer coefficients in coarse-resolution ocean circulation models, J. Phys. Oceanogr., 27, 381-402, doi:10.1175/15200485(1997)027<0381:SOETCI>2.0.CO;2, 1997.

Vollmer, L. and Eden, C.: A global map of mesoscale eddy diffusivities based on linear stability analysis, Ocean Model., 72, 198-209, 2013. 